News

\title{
Dream body/dreambody on the history and theory of processor-oriented psychology
}

Volume 9 Issue I - 2018

\section{News}

For most of us - even for many therapists - the body becomes a serious issue only when serious symptoms occur. After completing my Jungian education and Zurich and my qualification as a teaching analyst in the 1970s, I discovered the connection between body and dream. It became clear to me: when dreams are significant, this also applies to all dreamlike experiences. As a result, I realized how the dreaming mind is not only working in our nightly dreams, but somehow during the day in all that we notice in ourselves and around us. I was amazed to discover the dreaming process in our everyday consciousness and all our body sensations. Whatever we experience reflects subtly our dream experiences. On the basis of these observations, I developed what is now known as "Processoriented Psychology", a non-pathological approach to everything we experience, from body symptoms to dance and relationships to processes in large groups. In essence, I gained my assumptions about the nature of processes from physics and Taoism - on the background of my earlier studies of applied physics, Jungian psychology and Taos, "I do not know his name". I found new access routes to altered states of consciousness, including in psychosis and coma. And spiritual experiences appeared to me in a whole new light.

\section{Follow what you notice}

After studying many old and alternative medical practices, without knowing how to combine dream and body experiences, I remembered my science training and decided to just watch. I took every detail seriously, everything people did and said. I watched and listened, asked questions and tried to fathom what they meant and felt when talking about dreams, body experiences, relationships, and world politics. The results renewed my faith in the human mind, to the Tao. Dreambody - dream body This basic attitude of observation led to my first discovery. Dreams appear not only at night, but also in the daytime - in the form of symptoms. The dreams reflect us as our body symptoms feel for us as we experience them. A sharp pain that concentrates on a point often improves when we get to the point better in our daily behavior. At the beginning was the insight: body symptoms are part of the trauma process. The body dreams. This phenomenon that dreams reflect body sensations, I called Dreambody, "dream body". I wrote a series of books about this mirroring process. A case study from the book "The Dreambody" illustrates the connection between dream and body work: It was a man in his mid-fifties, suffering from a chronically elevated blood pressure (diagnosed by his physician as a hypertension) and a tormenting internal ear infection that had already spread over several months. He told me that his blood pressure is constantly at 220/160 and hardly appeals to medical treatment. Antibiotics would temporarily relieve the inflammation of the ears and throat, but if he withdraws the drug, he immediately falls ill again. My patient told me he was on Psychology has no interest whatsoever, and only consults me because his doctor thinks that it can be of use to him. He assured me that I was psychically absolutely
Arnold Mindell
Department of Psychology, Union Institute, USA

Correspondence: Arnold Mindell, Department of Psychology, Union Institute, USA, Email arny@aamindell.net

Received: November 25, 2016 | Published: January 03, 2018

normal. His daily life was quite satisfying, except that he sometimes felt as if he were under pressure at work.

To my question, what striking feelings he felt at the moment, he replied that his ear disturbed him. With this signal, we started our work. I asked him to describe his earache. His ear just hurt him! I asked him how it hurt, which, according to his imagination, could cause this pain, and what might make the pain even worse? He responded to my question with the remark that my idea of intensifying the pain was very odd to him. Rather, he had always tried to achieve the opposite. He had only asked his doctor to get medication for the earaches. Then he wanted to know what I was doing. The man was an academician and relied heavily on rational thought; So I tried to answer his questions intellectually. I told him that my study of Jungian psychology had taught me to amplify dream symbols with the help of associations from everyday life in order to interpret the meaning of dreams. In the same way, I would have begun to amplify body signals "physiologically", since I would have determined that these symptoms often then lessened and then, as a result of my work, explained to the dreamer himself. There is much to be understood under amplification, but in its simplest form it also means the amplification of the intensity of physical signals. My explanation sounded sound in my patient's ears, and he was ready to amplify his earache. But when he tried, he felt blocked. He concluded that the path blocked him and was therefore not suitable for him. I agreed with him and pointed out that bodywork was not for everyone. There are other means to get to the causes of a body problem, except to experience it. Perhaps we could spend more time getting to know each other and talking about his feeling of being under time pressure. Bodywork is not an absolute means to be used at will and under all circumstances. In contrast to other, more reflective methods, the application depends on the personality of a person, the relationship to his or her body, but also the training and personality of the therapist. Sometimes bodywork is out of place and there are people who prefer to approach the body by means of tramprocesses. In fact, body work can begin spontaneously in the middle of a dream interpretation. My patient surprised me with 
a remark that all paths were the same for him, and that he wanted to make an attempt to amplify his earaches. He thought for a moment, then thought it was as if something were coming from within. How this "something" comes from inside, I wanted to know. He looked at me for a moment with raised eyebrows, then closed his eyes and began to meditate on "pushing". He took a deep breath and held the air for a remarkably long time. I have! - Pressure and pain can be caused when I hold my breath, close my mouth, and at the same time try to expel the air through the closed lips. "I also tried to stop the air in this way to experience the sensations described by him. Why is it helpful for the therapist to imitate what the patient is doing? It is not a "must", but experience has shown me that the therapist can become more familiar with dreams or body problems through conscious empathy with a psychological or physical experience. Even if these signals of communication do not become aware of him, he often mimics them unconsciously anyway. That is, he intuitively guesses the dream statement without knowing exactly where this speculation comes from, or he gets sick without being able to bring his own body symptoms together with the condition of his patient. Contrary to this unconscious behavior, conscious empathy and amplification of such processes can be mentally relaxing and physically relieving for the therapist.

My patient and I were still experimenting for a while by alternately holding our breaths and expelling them. After a while he said his ear was pressing to stop, because he was giggling, not being pressured or forced to do anything. The ear said, "Either you stop pushing, or I hurt you!" Again the man held his breath, pushed out as before the air and then stopped. He sat quietly and meditated. Suddenly, he opened his eyes excitedly and told me he had discovered something. The feeling of pressure that causes the pain of the ear is the same, which he feels in his neck and ears when his blood pressure is very high. So his high blood pressure must be related to the pressure, stress and the agitation he is doing to himself. His ear and the rest of the body demanded the pressure to "stop". He just had an idea how he could use these sensations in the ear and neck to end his drive. He would try to change his way of life. Before he left my practice, I inquired whether he had been dreaming lately. Yes, last night - from the police, who just mafia bosses arrested. To the word Mafia he associated "power" and then laughed. He had spontaneously interpreted his dream: his ear corresponded to the police. He wanted to capture the mafia-like pressure which he exerted on himself. I have discussed this case for various reasons. At first, the intellectual background of my patient forced me to formulate more psychological theory than I might have done differently with someone else. Secondly, amplifying the ear and pressure symptoms shows how dream body work can be used as a tool within trauma analysis. Furthermore, it is clear from this case how bodywork helps the dreamer to spontaneous insights. Fourthly, this example shows how two seemingly unrelated body problems, such as hypertension and earache, are interrelated. Over the years I have tried to find explanations for these phenomena and to form theories. The only idea which could be sustained and verified in this whole period is that of the dream body. The dream body is the basic unit of a person expressed in body symptoms as in tramprocesses. ${ }^{1}$

\section{The secrets of the body and the psychology}

The incredible experiences that I found "enclosed" in my clients' bodies filled me with awe. I was not only touched by the pain and anxiety that caused these symptoms, but also by the traumatic experiences of such insignificant appearances as a small itch. I started working with people close to death. It turned out that her body experiences revealed ancient wisdom that was only waiting to be brought up. I quite respect the allopathic approach to the body, but it touches only one aspect of the body experience. Another level of the body connects us to our innermost sense of space and time, to life itself. As I pursued apparently senseless pathological symptoms, and even the bizarre, almost unintelligible secrets of coma states, I opened myself to new ways of understanding psychological growth . The body proved to be a process with its own inner logic and as a trustworthy leader when it comes to dreaming and understanding "reality".

\section{The dream body in the world}

In the search for new ways of work with the body and with dreams, my process-oriented attitude led me to discover that dreams occur not only in the body, but occur in all sorts of other movements, such as relationships with their simple and ambiguous communication signals. A double signal is a body movement with a double message. I can say something while my body expresses something quite different. Normally we are aware of these double signals as little as the importance of our body symptoms and dreams. To look at these signals, clarifies and deepen our relationships. Relations are also an aspect of dreaming. In the course of time, I learned to follow the process of the dream body in relationships, and that led me to the perception of the dreaming process in large groups. This opened up new avenues for the understanding of conflicts and events at the international and global level. At the same time, the process-oriented training programs and schools have been developed.

\section{The first signs ( "pre-signals") of the dream body}

As the century progressed, I returned to physics. I wanted to know more about the origin of dreams and body experiences. What is life? Who are we? How did our universe arise? To explore the dream body, our physical-physical experience and our relationship to the universe, I turned back to the realm of quantum physics and physiology. I began to look for body experiences in the form of small first symptoms of symptoms. The observation of this happening, so to speak, in the Nanobereich led me to realize that a large part of quantum physics is the result of the projection of our finest feelings, our most subtle souls, is part of the Unus mundus of the C.G. Young has spoken.

\section{Coma work}

Now I was able to reconcile my current practice with my earlier studies and with the work of other natural scientists. In my day-today psychotherapeutic practice, another horizon was opened when we focused our attention not only on everyday difficulties but on the smallest, usually unobserved, perceptions. I was interested in working with signals that are almost unfeeling and barely pronounced. This became particularly clear when working with comapatients. I began to work with sick people on the threshold of death. First they came to my practice, later I went to their hospital. I often spoke to them before I could physically work with them. And then I watched people close to death. I worked with them just before surgery and shortly thereafter, when they were still under anesthesia, I listened to them, registered as they breathed, moving-as a scientific observer. I tried to take what I saw and heard very seriously: her deep breathing, her open eyes, her peculiar noises and sounds. Instead of thinking: that's because they are just awakening from anesthesia, I told myself: these might be meaningful, meaningful signals. Let me follow them. And the people woke up from the coma and made surprising, profound statements, symbolic things that were to be understood and which I took seriously. By believing in man, I discovered that in these deeply altered states of consciousness they experienced meaningful experiences. And 
I could talk to them, but just listen and hold their hand while they intersect these altered states of consciousness and follow their states and encourage them to go further. I told them, "Believe in what they are experiencing, take it seriously. More you do not have to do it.You just need to know that what you experience is the way.It is the only way we know. "And then the people began to mutter and I told them," That's right, that's a good murmur."

\section{The field in the background}

\section{At this time of my work with people in changed states of consciousness}

I received invitations from all over the world for lectures and workshops. My interest in the people I met with made me more and more interested in how this process could be applied to problems in groups and organizations. In this context I was able to contribute my scientific background and use the physical field theory. I combined Jung's collective unconscious with Rupert Sheldrakes' theory of the morphogenetic field and made clear how these concepts apply analogously to work with the human field. My work hypothesis is that the individual is part of a field. The field in the background that is also behind the concept of the collective unconscious. We Cannot exit from this field. We do not know exactly, but we feel that things happen in the background that determines our behavior. What I can do as an individual is to work on myself and to know that my experiences, everything I experience, is part of the field in which I am. Whatever one does, the field influences. Whatever happens in the field affects each of us The first step is to experience one's own experiences. The second is to communicate it to others in a coherent way and then learn to observe the feedback. This is how you work with the field. Your experience is important, it must be expressed, and you must be open to the experiences of others. The experiences want to get to know each other and work together. This is like working with the dreams of groups. This is world work. This is how transformation occurs. Dr. Arny Mindell, a graduate of the Massachusett Institute of Technology (MIT), a psychoanalyst in his own practice in Portland, Oregon, was a Jungian teacher analyst who developed the processoriented psychology (POP) Mrs. Amy teaches worldwide. He is the author of 19 books in 20 languages. The Dreambody " "The Dreams and Dreams “, Paderborn 1988," Traumkörper-Arbeit “, Paderborn 1993," Traumkörper in Beziehungen “, Basel 1994,” Mitten im Feuer “, Munich 1997 and a contribution In "Dear CG Young. What I always wanted to tell you ", edited by Marianne Schiess, Düsseldorf, 2000. Arny Mindell, among others, became known for his connection with psychology and physics, his work in near-death situations and working in international conflict situations such as poverty and racism.

\section{Acknowledgements}

None.

\section{Conflict of interest}

None.

\section{Funding}

None. 